Research Article

\title{
The U-Shaped Association between Bilirubin and Diabetic Retinopathy Risk: A Five-Year Cohort Based on 5323 Male Diabetic Patients
}

\author{
Miao Liu $\mathbb{D}$, Jianhua Wang, and Yao He $\mathbb{D}$ \\ Institute of Geriatrics, Beijing Key Laboratory of Aging and Geriatrics, National Clinical Research Center for Geriatrics Diseases, \\ State Key Laboratory of Kidney Diseases, Chinese PLA General Hospital, 28 Fuxing Road, Beijing 100853, China \\ Correspondence should be addressed to Yao He; yhe301@x263.net
}

Received 14 May 2018; Revised 23 August 2018; Accepted 11 September 2018; Published 30 October 2018

Guest Editor: Markus Wallner

Copyright ( 92018 Miao Liu et al. This is an open access article distributed under the Creative Commons Attribution License, which permits unrestricted use, distribution, and reproduction in any medium, provided the original work is properly cited.

\begin{abstract}
Aims. This study aimed at assessing the impact of baseline bilirubin (TBiL) on the incidence of diabetic retinopathy (DR) based on a five-year cohort study which consisted of 5323 Chinese male diabetic patients. Methods. A cohort study based on 5323 male diabetic patients was conducted in Beijing, from 2009 to 2013. Both baseline TBiL and follow-up changes were measured. Cox proportional risk model was used to calculate the hazard ratio (HR) of TBiL for DR risk. Results. During the follow-up period, there were 269 new DR cases. The incidence of five-year follow-up was 5.1\% (95\% CI: 4.5\% 5.6\%). The TBiL level of those who had diabetic retinopathy was lower than that of those without $(12.51+1.20 \mathrm{~mol} / \mathrm{L}$ and $13.11+1.32 \mu \mathrm{mol} / \mathrm{L}, P=0.033)$. And more interestingly, along with the quintiles of baseline TBiL, there showed a U-shaped curve with DR incidence. And the RRs were 0.928 (95\% CI: 0.646-1.331), 0.544 (95\% CI: 0.365-0.811), 0.913 (95\% CI: 0.629-1.324), and 1.035 (95\% CI: 0.725-1.479) for the second, third, fourth, and fifth quintiles of baseline TBiL levels, respectively, compared with the first quintile. For follow-up TBiL changes, after being adjusted for related covariables and baseline TBiL levels (as continuous variable) in the model, the RRs for DR were 1.411 (95\% CI: 1.081-1.842) for those who had decreased TBiL level and 0.858 (95\% CI: 0.770-0.947) for those who had increased TBiL level during follow-up. And this association was more prominent among those with lower baseline TBiL level. Conclusions. Serum TBiL had a U-shaped relationship with DR incidence, which was independent of control status of diabetes and other related covariates.
\end{abstract}

\section{Introduction}

Diabetic retinopathy (DR) is one of the important vascular complications of diabetes. Data show that this is the main cause of blindness among working age population in developing countries [1]. Therefore, exploring the pathogenesis of DR is of most importance [2]. Previous basic and clinical research data indicated that oxidative stress played an important role in the development of DR.

Total bilirubin (TBIL) has been considered as a powerful endogenous antioxidant in recent years. A number of studies have shown that elevated TBiL levels were negatively correlated with cardiovascular disease and diabetes mellitus [3-5]. In addition, a number of studies have reported a protective relationship between TBiL levels and diabetic vascular complications. There was also a meta-analysis of the association between TBiL and DR published in 2016 [6]. However, these studies were mostly cross-sectional or casecontrol studies with small sample sizes and inconsistent findings. Some studies show that there was no association between TBiL and DR risk [7, 8]. In addition, there was little evidence of dose-response effects, which was of great value in determining appropriate clinical thresholds of TBiL levels among diabetic patients. Therefore, based on this five-year 


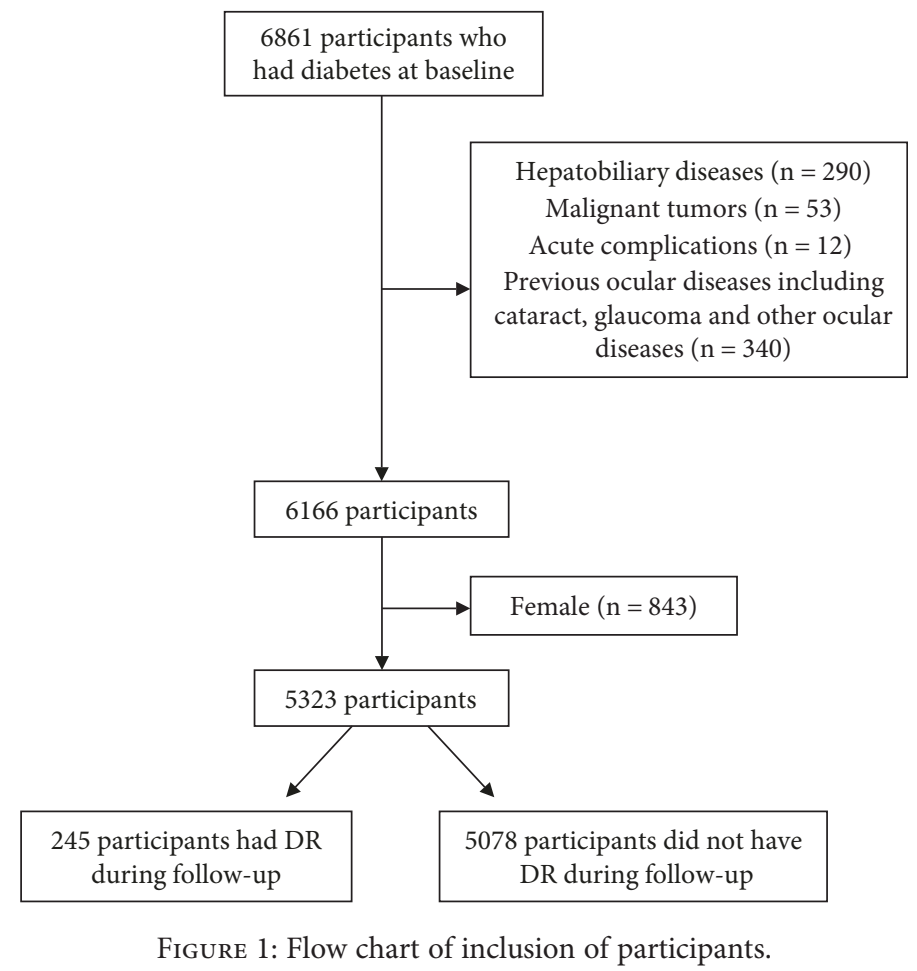

cohort study with a large sample (more than 5000 elderly diabetic patients), our study assessed the relationship between TBIL and its changes and the incidence of DR.

\section{Methods}

2.1. Subjects. This cohort study consisted of elderly diabetic patients. We conducted the baseline survey in 2009, and a total of 6861 elderly were recruited, and the follow-up survey was done in 2013. The details were described in a previous article [9]. Considering the possible effects of related diseases on TBiL or diabetes, we excluded those patients who had hepatobiliary diseases $(n=290)$, malignant tumors $(n=53)$, acute diabetic complications such as ketoacidosis $(n=12)$, previous ocular diseases including cataract, glaucoma, and other ocular diseases $(n=340)$. Considering female just accounted for $13.7 \%$ (843) of the total participants, only 5323 male participants were left for further analysis. Figure 1 shows the flow chart of participants' inclusion.

2.2. Data Collection. Baseline anthropometric and physical examination information was collected according to the standard process. Fasting blood was collected, and the related biochemical indexes were detected. The details were described in a previous article [9].

2.3. Definitions. The duration of diabetes was calculated by age minus the age of first diagnosis on diabetes. Quintiles of baseline TBiL level were defined as follows: Q1: $\leq 9.20 \mu \mathrm{mol} /$ L, Q2: $9.20-12.60 \mu \mathrm{mol} / \mathrm{L}, \quad$ Q3: $12.60-13.80 \mu \mathrm{mol} / \mathrm{L}, \quad$ Q4: $13.80-16.50 \mu \mathrm{mol} / \mathrm{L}$, and $\mathrm{Q} 5: \quad \geq 16.50 \mu \mathrm{mol} / \mathrm{L}$. Follow-up changes of TBiL were defined as follow-up TBiL levels minus baseline TBiL levels and were divided into three categories: $\leq-2 \mu \mathrm{mol} / \mathrm{L} ;-2$ to $2 \mu \mathrm{mol} / \mathrm{L} ;$ and $\geq 2 \mu \mathrm{mol} / \mathrm{L}$. Diabetes, hypertension, and dyslipidemia were defined according to the corresponding guidelines. DR was defined according to the Chinese version of guidelines for the prevention and treatment of type 2 diabetes: the presence of mild or moderate or proliferative retinopathy in either eye [10], and was independently diagnosed by two senior ophthalmologists.

2.4. Statistical Analysis. For continuous data, mean $\pm \mathrm{SD}$ was used for description, and analysis of variance was used for comparisons. For categorical variables, chi-square test is used for comparison. Multivariate Cox proportional hazard model was used to estimate the hazard ratio (HR) and $95 \%$ confidence intervals (CIs) of DR based on baseline TBiL levels and follow-up TBiL changes. Restricted cubic spline functions with 5 knots were used to test the potential nonlinear association and display the data graphically. SPSS software was used for data analysis. $P<0.05$ was statistically significant.

2.5. Ethical Consideration. The ethics committee of the General Hospital of PLA approved the study (EC0411-2001). Each participant signed a written informed consent.

\section{Results}

3.1. Baseline Characteristics according to DR Incidence. Table 1 shows the baseline characteristics of the subjects. The mean age of the 5323 diabetic patients was $78.68 \pm$ 8.39 (65 102 yrs). Mean diabetes duration and TBiL level were $17.25 \pm 7.49 \mathrm{yrs}$ and $13.08 \pm 1.32 \mu \mathrm{mol} / \mathrm{L}$. The percentage of overweight/obesity, hypertension, and dyslipidemia was $68.4 \%, 62.4 \%$, and $35.8 \%$, respectively. Compared with those who did not have DR, those with DR had relatively longer duration, higher FPG and 2hPG levels, and lower 
TABLE 1: General characteristics of participants according to DR incidence.

\begin{tabular}{|c|c|c|c|c|}
\hline Characteristics & $\operatorname{NDR}(n=5078)$ & $\mathrm{DR}(n=245)$ & $P$ & Total $(n=5323)$ \\
\hline \multicolumn{5}{|l|}{ Mean \pm SD } \\
\hline Age (yrs) & $78.68 \pm 8.41$ & $78.95 \pm 7.80$ & 0.623 & $78.68 \pm 8.39$ \\
\hline Duration (yrs) & $17.14 \pm 7.51$ & $19.81 \pm 7.40$ & 0.042 & $17.25 \pm 7.49$ \\
\hline Height $(\mathrm{cm})$ & $169.64 \pm 5.41$ & $169.22 \pm 5.18$ & 0.235 & $169.62 \pm 5.40$ \\
\hline Weight (kg) & $72.61 \pm 8.53$ & $72.66 \pm 8.51$ & 0.927 & $72.61 \pm 8.53$ \\
\hline BMI $\left(\mathrm{kg} / \mathrm{m}^{2}\right)$ & $25.24 \pm 2.79$ & $25.38 \pm 2.80$ & 0.446 & $25.24 \pm 2.79$ \\
\hline SBP (mmHg) & $133.28 \pm 14.04$ & $133.77 \pm 13.64$ & 0.593 & $133.30 \pm 14.02$ \\
\hline $\mathrm{DBP}(\mathrm{mmHg})$ & $73.88 \pm 9.46$ & $72.68 \pm 8.97$ & 0.052 & $73.82 \pm 9.44$ \\
\hline $\mathrm{Hb}(\mathrm{g} / \mathrm{L})$ & $132.11 \pm 15.44$ & $131.16 \pm 20.37$ & 0.848 & $132.07 \pm 17.83$ \\
\hline $\mathrm{TC}(\mathrm{mmol} / \mathrm{l})$ & $4.75 \pm 1.05$ & $4.68 \pm 1.00$ & 0.307 & $4.75 \pm 1.05$ \\
\hline TG $(\mathrm{mmol} / \mathrm{l})$ & $1.68 \pm 1.08$ & $1.59 \pm 1.00$ & 0.196 & $1.67 \pm 1.07$ \\
\hline HDL-C (mmol/l) & $1.33 \pm 0.44$ & $1.23 \pm 0.32$ & $<0.001$ & $1.33 \pm 0.44$ \\
\hline LDL-C (mmol/l) & $2.67 \pm 0.83$ & $2.74 \pm 0.83$ & 0.186 & $2.67 \pm 0.83$ \\
\hline $\mathrm{FPG}(\mathrm{mmol} / \mathrm{l})$ & $6.93 \pm 1.89$ & $6.95 \pm 1.92$ & 0.046 & $6.94 \pm 1.90$ \\
\hline 2hPG (mmol/l) & $9.24 \pm 2.83$ & $9.96 \pm 2.35$ & $<0.001$ & $9.27 \pm 2.86$ \\
\hline $\operatorname{ALT}(\mathrm{U} / \mathrm{L})$ & $20.81 \pm 4.59$ & $19.91 \pm 4.99$ & 0.041 & $20.76 \pm 4.68$ \\
\hline Baseline TBiL $(\mu \mathrm{mol} / \mathrm{L})$ & $13.11 \pm 1.32$ & $12.51 \pm 1.20$ & 0.033 & $13.08 \pm 1.32$ \\
\hline \multicolumn{5}{|l|}{$\%$} \\
\hline Education & & & 0.105 & \\
\hline$\leq 6 \mathrm{yrs}$ & 65.1 & 65.3 & & 65.4 \\
\hline$\geq 7 \mathrm{yrs}$ & 34.9 & 34.7 & & 34.6 \\
\hline Marriage status & & & 0.077 & \\
\hline Divorced/widowed & 16.5 & 12.3 & & 12.7 \\
\hline Married & 87.5 & 83.7 & & 87.3 \\
\hline Current smoking & & & 0.186 & \\
\hline Yes & 21.7 & 18.6 & & 21.5 \\
\hline No & 78.3 & 81.4 & & 78.5 \\
\hline Current alcohol drinking & & & 0.854 & \\
\hline Yes & 19.7 & 19.5 & & 18.7 \\
\hline No & 80.3 & 80.5 & & 80.3 \\
\hline Overweight/obesity & & & 0.640 & \\
\hline Yes & 68.4 & 69.8 & & 68.4 \\
\hline No & 31.6 & 30.2 & & 31.6 \\
\hline Hypertension & & & 0.171 & \\
\hline Yes & 62.2 & 66.5 & & 62.4 \\
\hline No & 37.8 & 33.5 & & 37.6 \\
\hline Dyslipidemia & & & 0.101 & \\
\hline Yes & 34.8 & 35.3 & & 35.8 \\
\hline No & 65.2 & 64.7 & & 64.2 \\
\hline Control of diabetes & & & 0.907 & \\
\hline Yes & 50.7 & 50.5 & & 50.8 \\
\hline No & 49.3 & 49.5 & & 49.2 \\
\hline
\end{tabular}

Data are mean \pm SD for continuous values or $\%$ for category values.

baseline TBiL level $(p<0.05)$. Baseline characteristics according to quintiles of baseline TBiL levels were presented in Appendix Table 1. Along with the increase of baseline TBiL levels, it showed shorter duration; higher Hb, HDL-C, FPG, and 2hPG levels; and lower percentage of diabetes control status.
3.2. Incidence of DR according to Baseline TBiL Quintiles and Follow-Up TBiL Changes. There were a total of 269 DR cases during the 21,586 person-years. The total five years' incidence was 5.1\% (95\% CI: 4.5\%-5.6\%). As we can see from Table 2, the incidence of the quintiles of baseline TBiL for DR had fluctuations; the third quintile 
TABLE 2: Incidence of DR according to baseline TBiL quintiles and follow-up TBiL changes.

\begin{tabular}{|c|c|c|c|c|c|c|c|c|c|}
\hline \multirow{2}{*}{ DR } & \multirow[b]{2}{*}{$\begin{array}{c}\text { Q1 } \\
(\leq 9.20)\end{array}$} & \multicolumn{3}{|c|}{ Quintiles of baseline TBiL $(\mu \mathrm{mol} / \mathrm{L})$} & \multirow[b]{2}{*}{$\begin{array}{c}\text { Q5 } \\
(\geq 16.50)\end{array}$} & \multicolumn{3}{|c|}{$\begin{array}{l}\text { Follow-up TBiL changes } \\
\qquad(\mu \mathrm{mol} / \mathrm{L})\end{array}$} & \multirow{2}{*}{ Total } \\
\hline & & $\begin{array}{c}\text { Q2 } \\
(9.20-12.60)\end{array}$ & $\begin{array}{c}\text { Q3 } \\
(12.60-13.80)\end{array}$ & $\begin{array}{c}\mathrm{Q} 4 \\
(13.80-16.50)\end{array}$ & & $\leq-2$ & -2 to 2 & $\geq 2$ & \\
\hline $\begin{array}{l}\text { Number of incident } \\
\text { cases }\end{array}$ & 61 & 57 & 40 & 51 & 60 & 115 & 105 & 49 & 269 \\
\hline Incidence (\%) & $\begin{array}{c}5.6 \\
(4.3-7.0)\end{array}$ & $\begin{array}{c}5.4 \\
(4.0-6.8)\end{array}$ & $\begin{array}{c}3.4 \\
(2.4-4.5)\end{array}$ & $\begin{array}{c}5.2 \\
(3.8-6.2)\end{array}$ & $\begin{array}{c}5.7 \\
(4.3-7.1)\end{array}$ & $\begin{array}{c}6.3 \\
(5.2-7.5)\end{array}$ & $\begin{array}{c}4.9 \\
(4.0-5.9)\end{array}$ & $\begin{array}{c}3.7 \\
(2.7-4.8)\end{array}$ & $\begin{array}{c}5.1 \\
(4.5-5.6)\end{array}$ \\
\hline Total person-years & 4399 & 4302 & 4638 & 3981 & 4267 & 7443 & 8692 & 5451 & 21,586 \\
\hline $\begin{array}{l}\text { Incidence density } \\
\text { (per } 100 \text { person-years) }\end{array}$ & $\begin{array}{c}1.4 \\
(1.1-1.8)\end{array}$ & $\begin{array}{c}1.3 \\
(1.0-1.7)\end{array}$ & $\begin{array}{c}0.9 \\
(0.6-1.2)\end{array}$ & $\begin{array}{c}1.3 \\
(1.0-1.7)\end{array}$ & $\begin{array}{c}1.4 \\
(1.1-1.8)\end{array}$ & $\begin{array}{c}1.5 \\
(1.3-1.9)\end{array}$ & $\begin{array}{c}1.2 \\
(1.0-1.5)\end{array}$ & $\begin{array}{c}0.9 \\
(0.7-1.2)\end{array}$ & $\begin{array}{c}1.2 \\
(1.1-1.4)\end{array}$ \\
\hline
\end{tabular}

TABLE 3: HRs and 95\% CI of DR incidence according to baseline TBiL levels $(\mu \mathrm{mol} / \mathrm{L})$.

\begin{tabular}{lcc}
\hline Variable type & $\mathrm{HR}^{*}(95 \% \mathrm{CI})$ & $P$ \\
\hline Continuous variable & $0.956(0.934-0.983)$ & 0.001 \\
Quintiles & $1.838(1.233-2.740)$ & 0.017 \\
Q1 $(\leq 9.20)$ & $1.705(1.138-2.555)$ & \\
Q2 $(9.20-12.60)$ & $1.00($ Ref $)$ & \\
Q3 (12.60-13.80) & $1.678(1.109-2.540)$ & \\
Q4 (13.80-16.50) & $1.903(1.275-2.841)$ & \\
Q5 ( $\geq 16.50)$ &
\end{tabular}

*Adjusted for age, marital status, current smoking, current alcohol drinking, BMI, baseline $\mathrm{Hb}, \mathrm{ALT}$, baseline prevalence of hypertension and dyslipidemia, control of diabetes, duration of diabetes, and follow-up TBiL changes (as continuous variable) in the model.

had the lowest incidence while the first and the fifth had the highest incidence. The incidence density showed a similar trend. The incidence of follow-up TBiL changes for DR was lowest among those who had an increase of $\geq 2 \mu \mathrm{mol} / \mathrm{L}$ while highest among those who had a decrease of $\leq-2 \mu \mathrm{mol} / \mathrm{L}$ (Table 2).

3.3. HRs and 95\% CI of DR Incidence according to Baseline TBiL Levels. Table 3 showed the HRs of baseline TBiL levels for DR incidence. We adjusted related covariables according to results of univariate analysis (Appendix Table 1); the HRs of baseline TBiL levels for DR were 0.9656 (95\% CI: 0.934$0.983)$. When quintiles were used as categorical variables, the HRs were 1.838 (95\% CI: 1.233-2.740), 1.705 (95\% CI: 1.138-2.555), 1.678 (95\% CI: 1.109-2.540), and 1.903 (95\% CI: 1.275-2.841) for the first, second, fourth, and fifth quintiles of baseline TBiL levels, respectively, compared with the third quintile. And restricted cubic spline functions depicted a sort of U-shaped curve (Figure 2).

3.4. HRs for DR Incidence according to Follow-Up TBiL Changes. The follow-up TBiL level was lower than the baseline TBiL level. The mean level of the baseline TBiL was $13.05 \pm 1.65$ (median: 12.30, IQR: 9.20-15.30) $\mu \mathrm{mol} / \mathrm{L}$, and the mean follow-up TBiL level was $12.54 \pm 1.64$ (median: 12.50, IQR: $10.00-15.70) \mu \mathrm{mol} / \mathrm{L}$; thereby, the follow-up

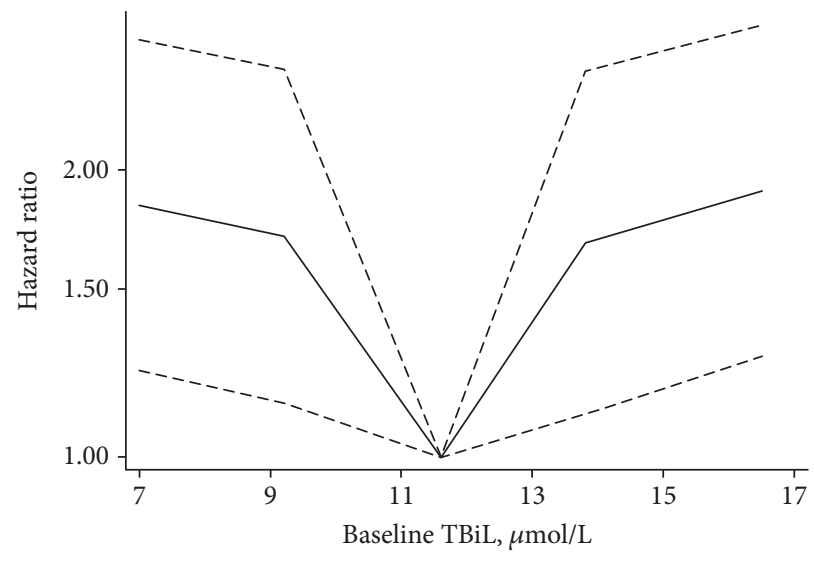

FIgURe 2: HRs of follow-up TBiL changes for DR incidence according to baseline TBiL level.

TBiL changes were $-0.66 \pm 1.93$ (median: -0.73 , IQR: -3.30 to 2.10$) \mu \mathrm{mol} / \mathrm{L}$ (Appendix Table 2). Those who had DR in the follow-up years had a relatively bigger TBiL change; the mean follow-up TBiL changes were $-1.60 \pm 1.48$ (median: -1.11 , IQR: -3.86 to 1.20$) \mu \mathrm{mol} / \mathrm{L}$.

For follow-up TBiL changes, after being adjusted for related covariables and baseline TBiL levels in the model, the HRs for DR were 0.967 (95\% CI: 0.944-0.991). When used as categorical variables, as we can see from Table 4, compared with those who had relatively stable TBiL levels $(-2 \mu \mathrm{mol} /$ $\mathrm{L}<$ follow-up TBiL changes $<2 \mu \mathrm{mol} / \mathrm{L}$ ), the HR for DR incidence was higher $(\mathrm{HR}=1.411,95 \% \mathrm{CI}$ : $1.081-1.842)$ among those who had follow-up TBiL changes $\geq 2 \mu \mathrm{mol} / \mathrm{L}$, and the $\mathrm{HR}$ was lower $(\mathrm{HR}=0.858,95 \% \mathrm{CI}$ : 0.770-0.947) among those with follow-up TBiL changes $\leq-2 \mu \mathrm{mol} / \mathrm{L}$. Besides, the decreasing trend of follow-up TBiL changes for DR incidence was more obvious among those with lower baseline TBiL level $(\leq 12.5 \mu \mathrm{mol} / \mathrm{L}, n=2669)$. However, among those with relatively higher baseline TBiL level $(>12.5 \mu \mathrm{mol} / \mathrm{L}$, $n=2654$ ), the HRs of follow-up TBiL changes showed no significant results.

In the sensitivity analysis, when participants who had DR that happened within less than 2 years were excluded $(n=37)$ or divided by age groups ( $\leq 80 \mathrm{yrs}$ and $>80 \mathrm{yrs}$ ), the trend of adjusted HRs was similar with the results from Tables 3 and 4 (Appendix Tables 3, 4, 5, and 6). 
TABLE 4: HRs and 95\% CI of DR incidence according to follow-up TBiL changes $(\mu \mathrm{mol} / \mathrm{L})$.

\begin{tabular}{|c|c|c|c|}
\hline & Variable type & $\mathrm{HR}^{*}(95 \% \mathrm{CI})$ & $P$ \\
\hline \multirow{5}{*}{$\begin{array}{l}\text { Total population } \\
(n=5323)\end{array}$} & $\begin{array}{l}\text { Continuous } \\
\text { variable }\end{array}$ & $\begin{array}{c}0.967 \\
(0.944-0.991)\end{array}$ & 0.006 \\
\hline & $\begin{array}{l}\text { Categorical } \\
\text { variable }\end{array}$ & & 0.011 \\
\hline & $\leq-2$ & $\begin{array}{c}1.411 \\
(1.081-1.842)\end{array}$ & \\
\hline & -2 to 2 & 1.00 (Ref) & \\
\hline & $\geq 2$ & $\begin{array}{c}0.858 \\
(0.770-0.947)\end{array}$ & \\
\hline \multirow{5}{*}{$\begin{array}{l}\text { Among those } \\
\text { with baseline } \\
\text { TBiL level } \leq \\
12.5 \mu \mathrm{mol} / \mathrm{L} \\
(n=2669)\end{array}$} & $\begin{array}{l}\text { Continuous } \\
\text { variable }\end{array}$ & $\begin{array}{c}0.964 \\
(0.931-0.986)\end{array}$ & 0.037 \\
\hline & $\begin{array}{l}\text { Categorical } \\
\text { variable }\end{array}$ & & 0.003 \\
\hline & $\leq-2$ & $\begin{array}{c}1.756 \\
(1.217-2.534)\end{array}$ & \\
\hline & -2 to 2 & 1.00 (Ref) & \\
\hline & $\geq 2$ & $\begin{array}{c}0.853 \\
(0.761-0.934)\end{array}$ & \\
\hline \multirow{5}{*}{$\begin{array}{l}\text { Among those } \\
\text { with baseline } \\
\text { TBiL level > } \\
12.5 \mu \mathrm{mol} / \mathrm{L} \\
(n=2654)\end{array}$} & $\begin{array}{l}\text { Continuous } \\
\text { variable }\end{array}$ & $\begin{array}{c}0.969 \\
(0.936-1.003)\end{array}$ & 0.072 \\
\hline & $\begin{array}{l}\text { Categorical } \\
\text { variable }\end{array}$ & & 0.794 \\
\hline & $\leq-2$ & $\begin{array}{c}1.059 \\
(0.689-1.626)\end{array}$ & \\
\hline & -2 to 2 & 1.00 (Ref) & \\
\hline & $\geq 2$ & $\begin{array}{c}0.864 \\
(0.451-1.654)\end{array}$ & \\
\hline
\end{tabular}

*Adjusted for age, marital status, current smoking, current alcohol drinking, BMI, baseline $\mathrm{Hb}$, ALT, baseline prevalence of hypertension and dyslipidemia, control of diabetes, duration of diabetes, and baseline TBiL levels (as continuous variable) in the model.

\section{Discussion}

In this study, we did a deep study and evaluated the relationship between baseline TBiL and DR incidence using a large cohort of more than 5000 male elderly. The results showed that baseline TBiL had a U-shaped relationship with DR incidence, rather than a simple linear relationship. And this association was independent of control status of diabetes and other related covariates. And more interestingly, increased follow-up TBiL changes had a higher DR risk, and this association was more prominent among those with lower baseline TBiL level.

There were several researches focused on relationships between TBiL level and DR risk [11, 12], even one metaanalysis published in 2016 [6]. Most of the previous studies showed that there was a negative relationship between TBiL and DR. However, the result of our deep study showed that the association between TBiL and DR risk was not a simple linear association but a U-shaped curve. From the metaanalysis of TBiL and DR, we could see that most studies were cross-sectional ones or case-control studies with a small sample. Our study was based on a five-year cohort which consisted of more than 5000 elderly diabetic patients. And this U-shaped curve was consistent with previous ones about relationships about TBiL with cardiovascular diseases. A cohort study based on 7685 middle-aged British men firstly revealed that there was a $\mathrm{U}$-shaped relationship between TBiL and risk of ischemic heart disease [13]. And in 2012, results from one of the biggest cohorts based on more than 130,000 patients who received statin treatment showed that a U-shaped association appeared between TBiL before statin prescription and coronary heart diseases [14]. Our result was consistent with these prospective studies [15]. And this implies that the DR risk would no longer decrease when baseline TBiL increased to a relatively higher level. Meanwhile, there were a series of evidences showing that a higher TBiL level (beyond normal range) indicated hepatocellular injuries, and the latter one was proved to be associated with increased risk of diabetes and cardiovascular disease [7]. Besides, the negative relationship might be part of the U-shaped curve, since most of the crosssectional studies were of small sample size. And the actual $\mathrm{U}$-shaped association might be the combination of antioxidation and liver toxicity effects.

The pathogenesis of DR has not been fully studied. Oxidative stress caused by high glucose is one of the hotspots of the current research [16]. TBiL, not only a metabolite of hemoglobin, is also considered to be an important endogenous antioxidant. Past studies have shown that TBiL has important protective effects on cardiovascular disease, diabetes, and diabetic macrovascular complications, mainly through anti-inflammatory and antioxidant effects $[17,18]$. For DR, studies have revealed that TBiL has significant protective effects [6]. And results from the first known human case of heme oxygenase-1 deficiency showed that TBiL at physiological concentration has strong antioxidant activity, which can prevent low-density lipoprotein lipid peroxidation, and results based on mice showed that $1 \mathrm{~mol} / \mathrm{L}$ direct bilirubin can remove about $2 \mathrm{~mol} / \mathrm{L}$ free radicals [19]. All these evidences support the protective effect of TBiL on DR. However, the premise is in the normal range. If the TBiL was beyond the normal range, it is most probably an indicator of liver damage, which was an important risk factor for diabetes and its complications. There were several prospective studies with large sample size including our study which have showed the protective effect of TBiL in the normal range and the harmful effect in the relative higher range for cardiovascular disease and diabetes (including its complications) $[14,15,20]$, which confirmed the U-shaped curve of TBiL for DR in our study. This implies that in clinical practice, the previous "higher TBiL indicates lower risk of complications" was not always right. Doctors should also pay enough attention to the abnormal range and whether there were liver toxicity effects.

Follow-up changes of TBiL also had protective effects on DR incidence, which indicated that medical workers should also pay attention to both the baseline and the fluctuation of TBiL levels among diabetic patients, and it will play an important role in predicting DR incidence. Most of the previous studies only assessed the relationship between baseline TBiL level and DR; however, only a few studies focused on 
the follow-up volatility. In our study, for those who had increased TBiL changes $(\geq 2 \mu \mathrm{mol} / \mathrm{L})$, the risk of DR incidence had increased about $40 \%$. And the more obvious decreasing trend among those with relatively lower baseline TBiL levels verified previous results about the U-shaped curve of the association between TBiL and DR risk.

As far as we know, this was the first study to analyze the relationship between TBiL and DR based on a large sample cohort in fully adjusted models. In addition, besides baseline TBiL levels, TBiL changes also had an independent and inverse impact on DR incidence. The cohort had rigorous investigation process, strict training for all the staff in the field survey, and high response rate because of the wellcontrolled follow-up system.

However, this study had the following limitations. First, TBiL was measured only once at either baseline or followup, so it could not reflect the actual fluctuations. Second, only TBiL was collected; there was no specific value for direct and indirect bilirubin levels, so it was impossible to distinguish the exact role of these two types. Third, all participants were retired male, whose economic and medical security was relatively good, and the representation was limited for the general population.

In summary, this large-sample cohort study had shown that TBiL and its changes in diabetic patients were independently associated with DR incidence, and this association was independent of both classical risk factors and diabetes control status. Clinical medical staff should pay attention to the monitoring of TBiL levels in order to early detect and better control DR.

\section{Abbreviations}

$\begin{array}{ll}\text { ALT: } & \text { Alanine aminotransferase } \\ \text { BMI: } & \text { Body mass index } \\ \text { CI: } & \text { Confidence interval } \\ \text { DBP: } & \text { Diastolic blood pressure } \\ \text { DR: } & \text { Diabetic retinopathy } \\ \text { FBG: } & \text { Fasting plasma glucose; } \\ \text { HDL-C: } & \text { High-density lipoprotein cholesterol } \\ \text { HR: } & \text { Hazard ratio } \\ \text { LDL-C: } & \text { Low-density lipoprotein cholesterol } \\ \text { SBP: } & \text { Systolic blood pressure } \\ \text { SD: } & \text { Standard deviation } \\ \text { TBiL: } & \text { Total bilirubin } \\ \text { TC: } & \text { Total cholesterol } \\ \text { TG: } & \text { Triglyceride } \\ \text { 2hPG: } & \text { Two-hour plasma glucose. }\end{array}$

\section{Data Availability}

Data was available on reasonable request and can be obtained from the corresponding author.

\section{Disclosure}

The views and opinions expressed in this paper are those of the authors and do not necessarily reflect the official position of the study sponsors.

\section{Conflicts of Interest}

The authors declare that they have no competing interest.

\section{Authors' Contributions}

M. L. and Y. H. contributed to the design of the study. All authors were involved in the analysis and interpretation of the data. J. H. W. and M. L. conducted the statistical analysis. M. L. and Y. H. worked on the drafting of the manuscript, which was thoroughly reviewed and approved by all the authors. Miao Liu and Jianhua Wang contributed equally to this work.

\section{Acknowledgments}

We thank Dr. Bin Jiang, Dr. Jiaqi Li, Dr. Xianyu Lv, and head nurse Yafeng Yan for the help in the field survey. This study is supported by research grants from the National Natural Science Foundation of China (81773502, 81703285), Beijing Natural Science Foundation (7174350), Beijing Municipal Science and Technology Commission (Z161100005016021), Beijing Nova Program (Z181100006218085), Opening Foundation of State Key Laboratory of Kidney Diseases (KF-01115), and Military Fund (15BJZ41, 17BJZ51).

\section{Supplementary Materials}

Appendix Table 1: the general characteristics of participants according to the quintiles of baseline total bilirubin (TBiL) levels. Appendix Table 2: the distribution (including mean, $\mathrm{SD}$, median, and interquartile range) of baseline, follow-up, and change of TBiL levels $(\mu \mathrm{mol} / \mathrm{L})$. Appendix Table 3: the HRs and 95\% CI of diabetic retinopathy (DR) incidence according to baseline TBiL levels $(\mu \mathrm{mol} / \mathrm{L}$ ) (excluding DR cases in the first two years) using the Cox model. Appendix Table 4: the HRs and 95\% CI of DR incidence according to follow-up TBiL changes $(\mu \mathrm{mol} / \mathrm{L})$ (excluding DR cases in the first two years) using the Cox model. Appendix Table 5: the HRs and 95\% CI of DR incidence according to baseline TBiL levels $(\mu \mathrm{mol} / \mathrm{L})$ (by different age groups, $\leq 80 \mathrm{yrs}$ vs. $>80$ yrs) using the Cox model. Appendix Table 6: HRs and 95\% CI of DR incidence according to follow-up TBiL changes ( $\mu \mathrm{mol} / \mathrm{L}$ ) (by different age groups, $\leq 80$ yrs vs. $>80 \mathrm{yrs}$ ) using the Cox model. (Supplementary Materials)

\section{References}

[1] C. C. Klaver, R. C. Wolfs, J. R. Vingerling, A. Hofman, and P. T. de Jong, "Age-specific prevalence and causes of blindness and visual impairment in an older population: the Rotterdam Study," Archives of Ophthalmology, vol. 116, no. 5, pp. 653658, 1998.

[2] F. Bragg, M. V. Holmes, A. Iona et al., "Association between diabetes and cause-specific mortality in rural and urban areas of China," Journal of the American Medical Association, vol. 317, no. 3, pp. 280-289, 2017.

[3] R. Kawamoto, D. Ninomiya, Y. Hasegawa et al., "Mildly elevated serum total bilirubin levels are negatively associated with carotid atherosclerosis among elderly persons with type 2 
diabetes," Clinical and Experimental Hypertension, vol. 38, no. 1, pp. 107-112, 2015.

[4] M. Liu, Y. Li, J. Li, X. Lv, and Y. He, "Elevated serum total bilirubin levels are negatively associated with major diabetic complications among Chinese senile diabetic patients," Journal of Diabetes and its Complications, vol. 31, no. 1, pp. 213217, 2017.

[5] J. Wang, X. Wu, Y. Li et al., "Serum bilirubin concentrations and incident coronary heart disease risk among patients with type 2 diabetes: the Dongfeng-Tongji cohort," Acta Diabetologica, vol. 54, no. 3, pp. 257-264, 2017.

[6] B. Zhu, X. Wu, K. Ning, F. Jiang, and L. Zhang, "The negative relationship between bilirubin level and diabetic retinopathy: a meta-analysis," PLoS One, vol. 11, no. 8, article e0161649, 2016.

[7] E. J. Huang, W. W. Kuo, Y. J. Chen et al., "Homocysteine and other biochemical parameters in type 2 diabetes mellitus with different diabetic duration or diabetic retinopathy," Clinica Chimica Acta, vol. 366, no. 1-2, pp. 293-298, 2006.

[8] X. Shang, C. Song, H. Shao, and D. Xu, "Association of the homocysteine and bilirubin with the diabetic retinopathy," Chinese Journal of Prevention and Control of Chronic Diseases, vol. 22, no. 5, pp. 523-525, 2014.

[9] M. Liu, J. Li, X. Lv, and Y. He, "Bilirubin and its changes were negatively associated with diabetic kidney disease incidence and progression: a five-year's cohort study based on 5323 Chinese male diabetic patients," Journal of Diabetes and its Complications, vol. 32, no. 11, pp. 1012-1017, 2018.

[10] C. D. Society, "Guidelines for the prevention and control of type 2 diabetes in China (2013 edition)," Chinese Journal of Diabetes, vol. 6, no. 7, pp. 447-498, 2014.

[11] S. Hamamoto, H. Kaneto, S. Kamei et al., "Low bilirubin levels are an independent risk factor for diabetic retinopathy and nephropathy in Japanese patients with type 2 diabetes," Diabetes \& Metabolism, vol. 41, no. 5, pp. 429-431, 2015.

[12] M. Yasuda, Y. Kiyohara, J. J. Wang et al., "High serum bilirubin levels and diabetic retinopathy: the Hisayama Study," Ophthalmology, vol. 118, no. 7, pp. 1423-1428, 2011.

[13] L. H. Breimer, G. Wannamethee, S. Ebrahim, and A. G. Shaper, "Serum bilirubin and risk of ischemic heart disease in middle-aged British men," Clinical Chemistry, vol. 41, no. 10, pp. 1504-1508, 1995.

[14] L. J. Horsfall, I. Nazareth, and I. Petersen, "Cardiovascular events as a function of serum bilirubin levels in a large, statin-treated cohort," Circulation, vol. 126, no. 22, pp. 25562564, 2012.

[15] M. Liu, J. Wang, J. Zeng, X. Cao, and Y. He, “Association of NAFLD with diabetes and the impact of BMI changes: a 5-year cohort study based on 18,507 elderly," The Journal of Clinical Endocrinology \& Metabolism, vol. 102, no. 4, pp. 1309-1316, 2017.

[16] C. R. Giordano, R. Roberts, K. A. Krentz et al., "Catalase therapy corrects oxidative stress-induced pathophysiology in incipient diabetic retinopathy," Investigative Opthalmology \& Visual Science, vol. 56, no. 5, pp. 3095-3102, 2015.

[17] A. Abbasi, P. E. Deetman, E. Corpeleijn et al., "Bilirubin as a potential causal factor in type 2 diabetes risk: a Mendelian randomization study," Diabetes, vol. 64, no. 4, pp. 1459-1469, 2015.

[18] A. J. Cox, M. C. Y. Ng, J. Xu et al., "Association of SNPs in the UGT1A gene cluster with total bilirubin and mortality in the Diabetes Heart Study," Atherosclerosis, vol. 229, no. 1, pp. 155-160, 2013.
[19] A. Yachie, Y. Niida, T. Wada et al., "Oxidative stress causes enhanced endothelial cell injury in human heme oxygenase-1 deficiency," Journal of Clinical Investigation, vol. 103, no. 1, pp. 129-135, 1999.

[20] X. Lai, Q. Fang, L. Yang et al., "Direct, indirect and total bilirubin and risk of incident coronary heart disease in the Dongfeng-Tongji cohort," Annals of Medicine, vol. 50, no. 1, pp. 16-25, 2017. 


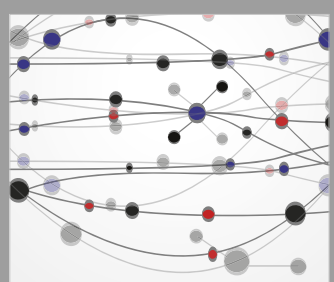

The Scientific World Journal
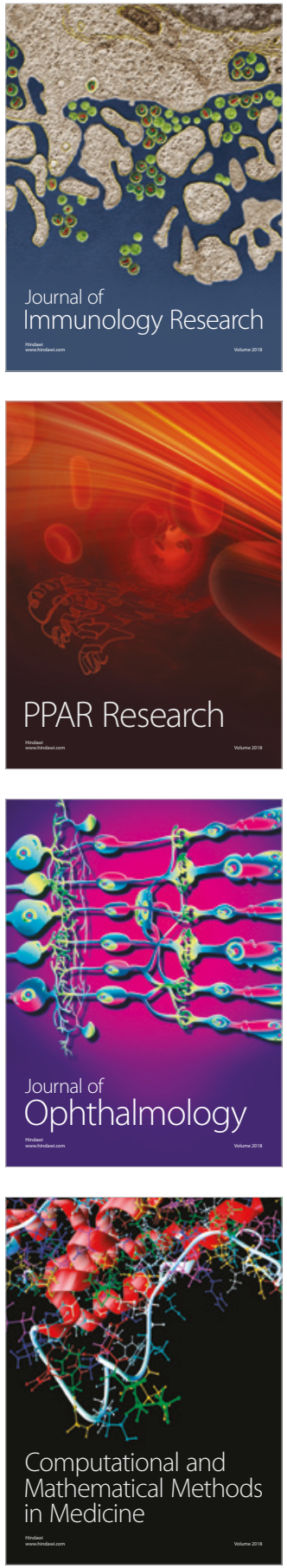

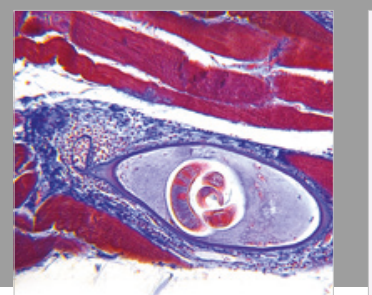

Gastroenterology Research and Practice

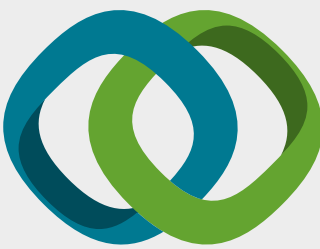

\section{Hindawi}

Submit your manuscripts at

www.hindawi.com
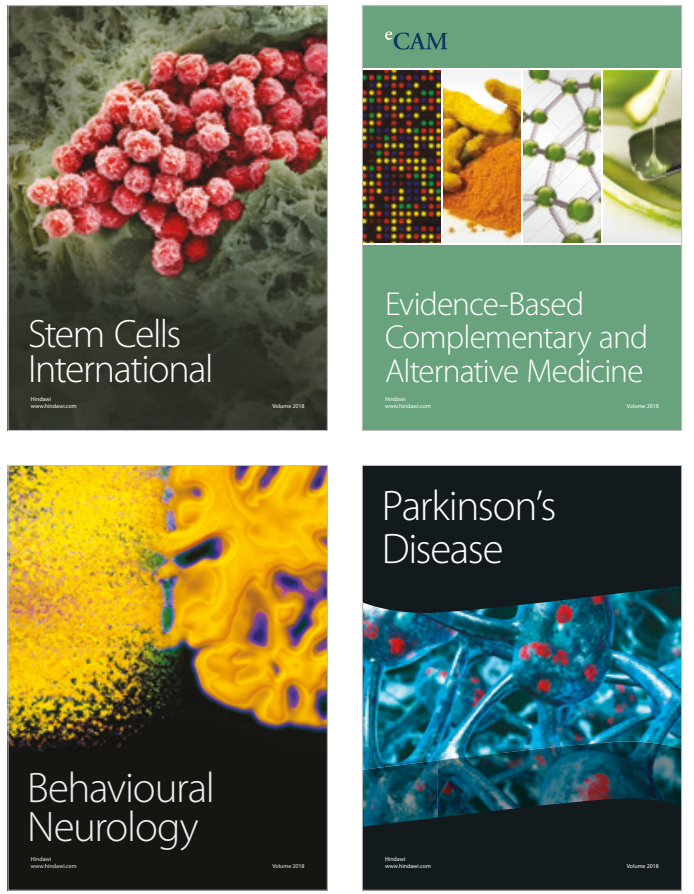

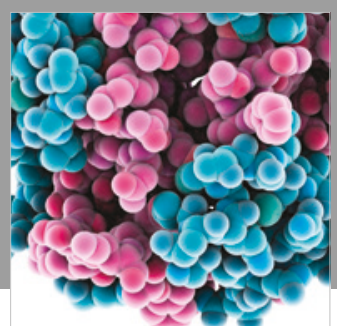

ournal of

Diabetes Research

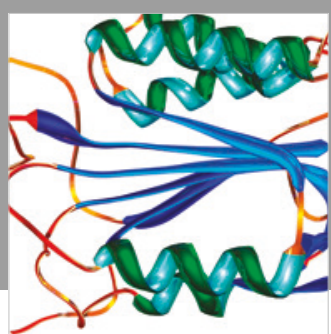

Disease Markers
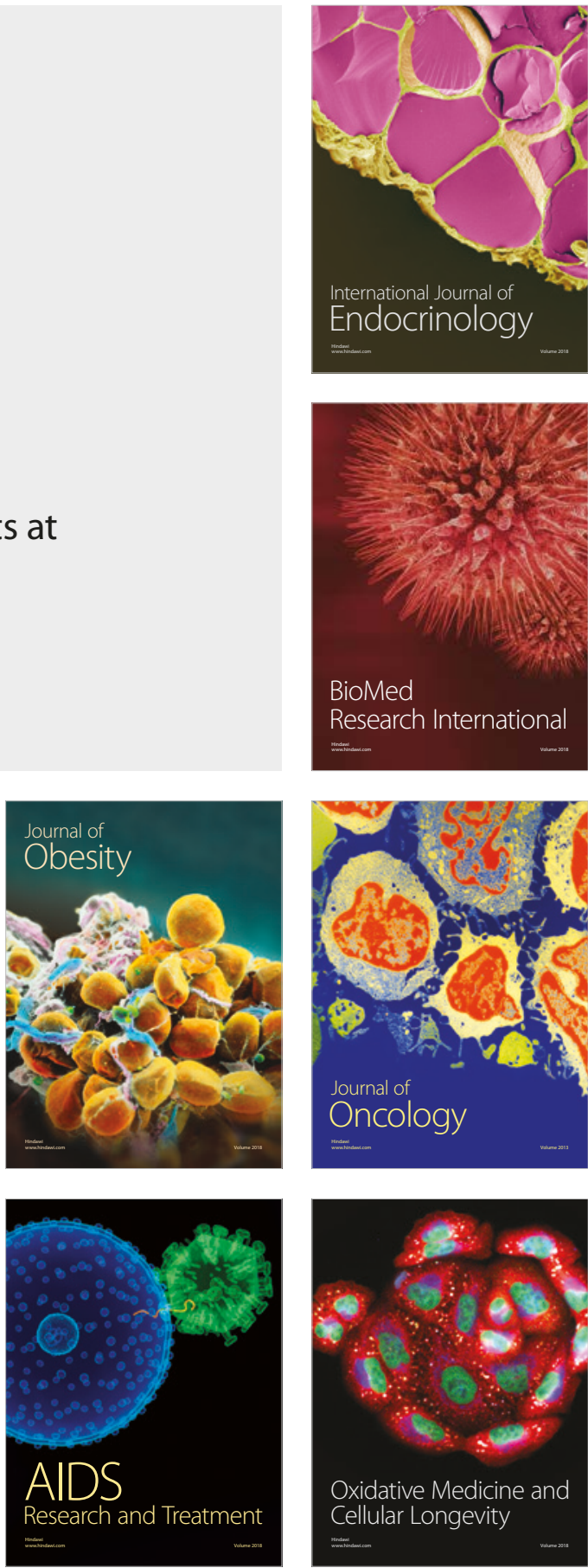